\title{
Contribution to Confirmed \& Synthesized on Mycorrhizae of Tuber indicum s.l. with Two Dominated \& Subalpine Broadleaf Trees in Southwestern China
}

\author{
Xiaojuan Deng1,2, Fuqiang Yu1, Peigui Liư ${ }^{*}$ \\ ${ }^{1}$ Key Laboratory of Biodiversity and Biogeography, Kunming Institute of Botany, Chinese Academy of Sciences, \\ Kunming, China \\ ${ }^{2}$ College of Biological Science and Engineering, Beifang University of Nationalities, Yinchuan, China \\ Email: ${ }^{*}$ pgliu@mail.kib.ac.cn
}

Received 18 August 2014; revised 21 September 2014; accepted 20 October 2014

Copyright (C 2014 by authors and Scientific Research Publishing Inc.

This work is licensed under the Creative Commons Attribution International License (CC BY).

http://creativecommons.org/licenses/by/4.0/

(c) (i) Open Access

\begin{abstract}
The ascomata and mycorrhizae of Tuber indicum s.l. were collected under the forest of broad-leaf species Populus yunnanensis and Quercus pannosa in the field respectively. The symbiotic relationships of both trees with $T$. indicum were examined and affirmed based on morphology and ITS-rDNA sequences. These two mycorrhizal combinations were successfully produced on artificially controlled substrates and cultural condition. This is the first report of a mycorrhizal association and synthesis between Chinese black truffles and poplars. A hyphal net covering the mantle's surface of the mycorrhizae was detected in both mycorrhizal combinations. The mycorrhizal colonization of $P$. yunnanensis and $Q$. pannosa suggests that $T$. indicum s.l. has a broader host range and that additional corresponding wood species would be used as candidates for the cultivation of $T$. indicum. The nuclear-ITS sequences of the mycorrhizae included in the phylogeny of the $T$. indicum complex revealed that the two clades within the complex do not markedly differ with respect to their preferences for host species or geographical origin. Our results help to explain the wide distribution of both clades of the $T$. indicum complex. It would be more important for truffle conservation and Chinese black truffle plantation development with these two dominated $\&$ alpestrine Populus yunnanensis and Quercus pannosa at subalpine limestone areas in China.
\end{abstract}

\section{Keywords}

Host Preference, Populus yunnanensis, Quercus pannosa, Mycorrhizae, Truffle, Conservation \& Plantation

\footnotetext{
${ }^{*}$ Corresponding author.
} 


\section{Introduction}

The Asian black truffle, Tuber indicum s.l., comprises a species complex that includes T. indicum Cooke \& Massee, T. himalayense B. C. Zhang \& Minter and T. sinense K. Tao \& B. Liu and is commercially important both in China and Europe as a result of its introduction to Europe in the 1990s. This commercial importance has motivated a series of studies on the taxonomy and phylogeny of this complex. Because these fungi are ectomycorrhizal, investigations into the symbiotic relationships of the $T$. indicum complex with trees are of practical and scientific importance. Several tree species are thought to be natural hosts: Quercus incana Roxb. for T. himalayense in Himalayan India [1] and Pinus armandii Franch. and Pi. yunnanensis Franch. for T. sinense in southwestern China [2] [3]. In a previous study that tested the ability of T. indicum s.l. taxa to form mycorrhizae on artificially controlled substrates, eight Chinese trees in the genera Quercus, Cyclobalanopsis, Carpinus, Pinus and Castanea were successfully inoculated with T. indicum s.l. [4]-[7]. Successful mycorrhizal synthesis was also observed for $T$. indicum s.l. and the North America trees P. taeda L. and Carya illinoinensis (Wangenh.) K. Koch [8] and the European trees Q. pubescens Willd., Q. cerris L., Q. ilex L., Corylus avellana L. and Pi. pinea L. [10]-[13].

Almost two decades of inappropriate collection and excessive commercialization have seriously threatened the natural sources of $T$. indicum s.l. in southwestern China [14]. To protect $T$. indicum s.l. while also meeting the market demand, Chinese mycologists are attempting to establish truffle plantations by producing truffle-colonized seedlings. Plantations of Cy. glauca colonized with $T$. formosanum, a species closely related to T. indicum s.l. [15], were reported to yield truffles eight years after transplantation [16]. The successful cultivation of $T$. formosanum implies that $T$. indicum s.l. plantations are feasible. The truffle plantation of Pinus armandii Franch. \& Castanea mollissima Blume infected with T. indicum respectively was set up in the spring of 2008, and begin to produce truffle fruit bodies fourth years after transplantation

(http://www.cas.cn/ky/kyjz/201212/t20121220_3725060.shtml). To achieve the goal of establishing such plantations, the first step is to determine which trees can be used as its hosts, an analysis that necessitates a reliable field record of the symbiotic relationships between T. indicum s.l. and tree species. However, in China, most of the reports on the host trees of $T$. indicum s.l. have been based on natural habitats, not on mycorrhizae collection and observation. The morphological details of mycorrhizae are also necessary to determine the quality of $T$. indicum s.l.-inoculated seedlings. Up to now, only the mycorrhizae of T. indicum s.l. on Castanea mollissima BL. and $P$. armandii have been described in China [5]. The widespread distribution of T. indicum s.l. in southwesttern China indicates that there are likely undiscovered mycorrhizal relationships. One objective of this work was to identify new natural hosts of T. indicum s.l. and to provide detailed descriptions of their mycorrhizae, and then to synthesis truffle mycorrhizae based on the results for the truffle conservation and plantation.

In recent years, phylogenetic studies have found that there are two phylogenetic clades within T. indicum s.l. [2] [9] [15] [17]-[23]. To explain this phylogenetic diversification, previous studies investigated the geographical and biological characteristics of the two clades. Using ITS-RFLP analysis, Paolocci et al. [20] suggested that geographical origin could contribute to the inter-clade variability. This hypothesis was supported by the study of Wang et al. [22]. However, after analyzing the origins, Zhang et al. [23] failed to find any correlation between phylogenetic relationships and either host or geographical origin. Chen et al. [15] obtained similar results, except that they found that $T$. formosanum, a small subclade within one of the two major clades in T. indicum s.l., should be treated as a separate species based on its exclusive association with Cy. glauca, its geographic distribution and its different morphology. Because all of the research was based on ascomata collected from markets or herbaria, the question about host preference or/and geographical contribution was unresolved. The objective of this work was to determine if there are differences in host preference or/and geographical range between different phylogenetic clades in the species complex of $T$. indicum by comparing the sequences of $T$. indicum s.l. mycorrhizae and ascomata collected in situ and look for new host trees.

\section{Materials and Methods}

\subsection{Sample Collections}

After collecting ascomata of $T$. indicum s.l. (the locations are listed in Table 1), the soil beneath the ascomata was removed until the mycorrhizae was visible. Approximately 30 mycorrhizal tips with soil were collected and stored in an ice box. All samples were transported to the laboratory within one week. The soil samples contain- 
Table 1. Information of samples for ITS sequences used in molecular analysis.

\begin{tabular}{|c|c|c|c|c|}
\hline Species name & Genbank No. & Source & Host & Locality \\
\hline T. indicum s.l. & JQ638967 & Natural mycorrhizae & Po. yunnanensis & Kunming, Yunnan \\
\hline T. indicum s.l. & JQ638968 & Natural mycorrhizae & Po. yunnanensis & Kunming, Yunnan \\
\hline T. indicum s.l. & JQ638963 & Natural mycorrhizae & Pi. armandii & Kunming, Yunnan \\
\hline T. indicum s.l. & JQ638964 & Natural mycorrhizae & Pi. armandii & Huize, Yunnan \\
\hline T. indicum s.l. & JQ638965 & Natural mycorrhizae & Pi. armandii & Huize, Yunnan \\
\hline T. indicum s.l. & JQ638966 & Natural mycorrhizae & Pi. armandii & Huize, Yunnan \\
\hline T. indicum s.l. & JQ638971 & Natural mycorrhizae & Pi. armandii & Dali, Yunnan \\
\hline T. indicum s.l. & JQ638973 & Natural mycorrhizae & Pi. armandii & Panzhihua, Sichuan \\
\hline T. indicum s.l. & JQ638974 & Natural mycorrhizae & Pi. armandii & Panzhihua, Sichuan \\
\hline T. indicum s.l. & JQ638962 & Natural mycorrhizae & Pi. yunnanensis & Kunming, Yunnan \\
\hline T. indicum s.l. & JQ638969 & Natural mycorrhizae & Pi. yunnanensis & Kunming, Yunnan \\
\hline T. indicum s.l. & JQ638970 & Natural mycorrhizae & Pi. yunnanensis & Kunming, Yunnan \\
\hline T. indicum s.l. & JQ638972 & Natural mycorrhizae & Ca. mollissima & Chuxiong, Yunnan \\
\hline T. indicum s.l. & JQ638975 & Natural mycorrhizae & Q. pannosa & Gongshan, Yunnan \\
\hline T. indicum s.l. & JQ638976 & Natural mycorrhizae & Q. pannosa & Gongshan, Yunnan \\
\hline T. indicum s.l. & JQ638977 & Synthesized mycorrhizae & Pi. armandii & \\
\hline T. indicum s.l. & JQ638978 & Synthesized mycorrhizae & Pi. armandii & \\
\hline T. indicum s.l. & JQ638979 & Synthesized mycorrhizae & Pi. armandii & \\
\hline T. indicum s.l. & JQ638980 & Synthesized mycorrhizae & Pi. armandii & \\
\hline T. indicum s.l. & JQ638981 & Synthesized mycorrhizae & Pi. armandii & \\
\hline T. indicum s.l. & JQ638953 & Synthesized mycorrhizae & Ca. mollissima & \\
\hline T. indicum s.l. & JQ638954 & Synthesized mycorrhizae & Ca. mollissima & \\
\hline T. indicum s.l. & JQ638956 & Synthesized mycorrhizae & Ca. mollissima & \\
\hline T. indicum s.l. & JQ638957 & Synthesized mycorrhizae & Ca. mollissima & \\
\hline T. indicum s.l. & JQ638955 & Synthesized mycorrhizae & Ca. mollissima & \\
\hline T. indicum s.l. & JQ638959 & Synthesized mycorrhizae & Ca. mollissima & \\
\hline T. indicum s.l. & JQ638984 & Ascomata & & Kunming, Yunnan \\
\hline T. indicum s.l. & JQ638985 & Ascomata & & Kunming, Yunnan \\
\hline T. indicum s.l. & JQ638986 & Ascomata & & Kunming, Yunnan \\
\hline T. indicum s.l. & JQ638987 & Ascomata & & Kunming, Yunnan \\
\hline T. indicum s.l. & JQ638988 & Ascomata & & Kunming, Yunnan \\
\hline T. indicum s.l. & JQ638989 & Ascomata & & Kunming, Yunnan \\
\hline T. indicum s.l. & JQ638990 & Ascomata & & Huize, Yunnan \\
\hline T. indicum s.l. & JQ638991 & Ascomata & & Huize, Yunnan \\
\hline T. indicum s.l. & JQ638992 & Ascomata & & Huize, Yunnan \\
\hline T. indicum s.l. & JQ638993 & Ascomata & & Huize, Yunnan \\
\hline T. indicum s.l. & JQ638994 & Ascomata & & Chuxiong, Yunnan \\
\hline T. indicum s.l. & JQ638995 & Ascomata & & Dali, Yunnan \\
\hline T. indicum s.l. & JQ638996 & Ascomata & & Dali, Yunnan \\
\hline
\end{tabular}




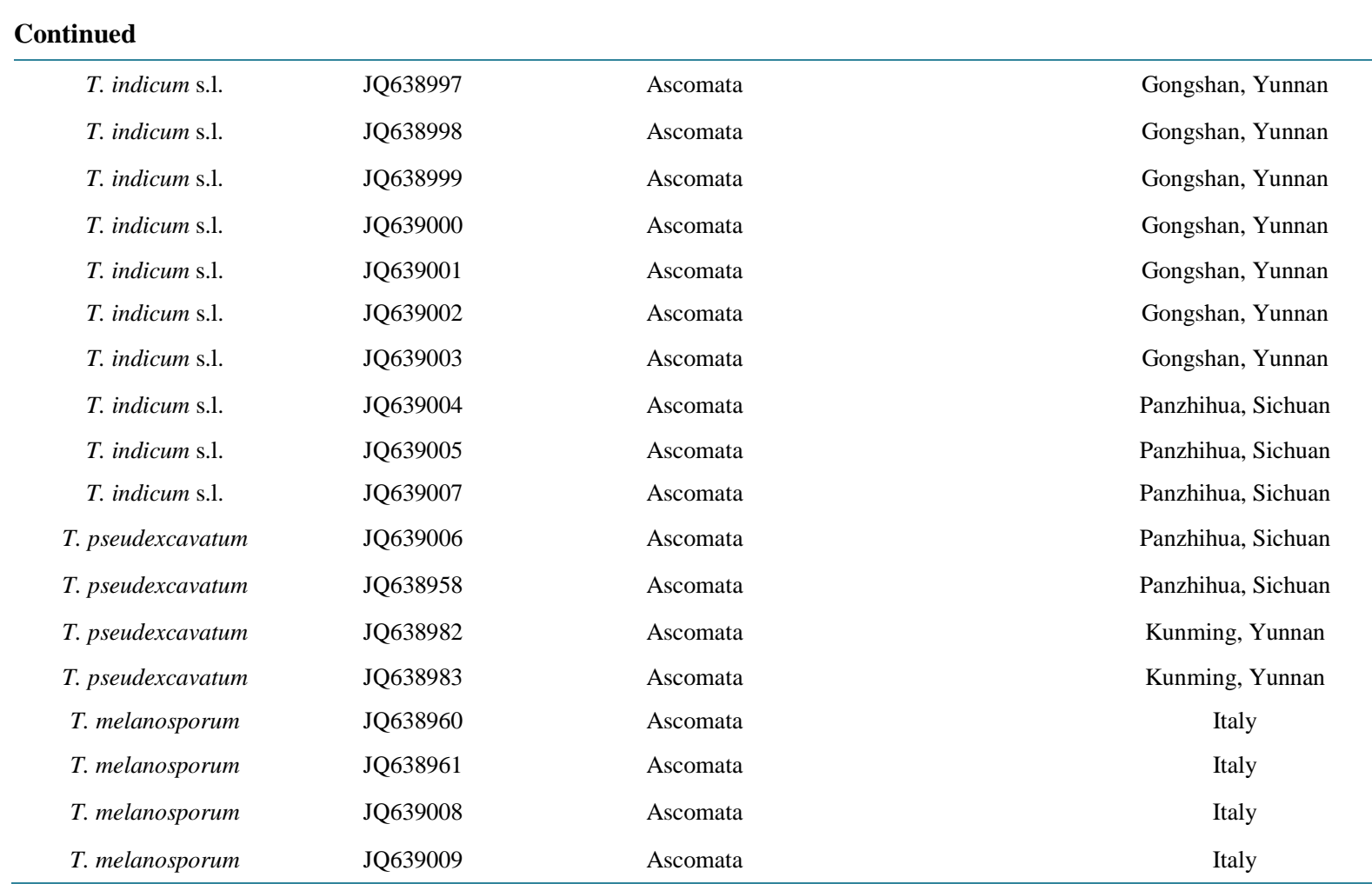

ing the mycorrhizae were placed in large dishes and soaked in water until the soil debris could be removed from mycorrhizae with needles. After being cleaned, the freshly isolated mycorrhizae were ready for morphological observation and DNA extraction. The host trees of the mycorrhizal samples used in this study is listed in Table 1.

\subsection{Morphological Study}

The macroscopic and microscopic characters of mycorrhizae were described and illustrated based on the descriptions of natural mycorrhizae by Agerer [24]. The mycorrhizae were photographed under a Nikon SMZ1500 stereoscope. Cross- and longitudinal sections of the mycorrhizae were prepared with a Leica CM1100 freezing microtome. The mantle layers and the anatomical structures of the hyphae were sectioned by hands. All anatomical sections were observed under a Nikon Eclipse E400 microscope and photographed with a Nikon E4500 camera.

\subsection{DNA Extraction, PCR Amplification and Sequencing}

DNA was extracted from ascomata or 6 - 10 mycorrhizal tips using the CTAB method (Doyle, 1987 [25]) with the minor modification of adding $200 \mu \mathrm{L}$ of $5 \mathrm{M}$ potassium acetate after the treatment with $4 \times \mathrm{CTAB}$. The ITS5 primers [26] and ITS4LNG [27] were used to amplify the ITS region from the ascomata or mycorrhizal samples to confirm the identities of the fungi in the mycorrhizae using blast (http://blast.ncbi.nlm.nih.gov/Blast.cgi). The final amplification reactions $(25 \mu \mathrm{L})$ contained $10 \mathrm{mM}$ Tris- $\mathrm{HCl}(\mathrm{pH} 9.0), 50 \mathrm{mM} \mathrm{KCl}, 1 \mathrm{mM} \mathrm{MgCl}, 100 \mu \mathrm{M}$ of each dNTP, $0.2 \mu \mathrm{M}$ of each primer, $1.5 \mathrm{U}$ of Taq Polymerase (Takara Taq, Takara Biotechnology, Dalian Co. Ltd., China), $0.2 \mu \mathrm{L}$ of BSA (1\%) and 50 ng of DNA template. The cycling parameters were an initial denaturation at $95^{\circ} \mathrm{C}$ for $5 \mathrm{~min}$; 35 cycles of denaturation at $94^{\circ} \mathrm{C}$ for $1 \mathrm{~min}$, annealing at $52^{\circ} \mathrm{C}$ for $45 \mathrm{~s}$ and extension at $72^{\circ} \mathrm{C}$ for $45 \mathrm{~s}$; and a final extension at $72^{\circ} \mathrm{C}$ for $10 \mathrm{~min}$. The amplification products were electrophoresed on a 1.2\% agarose gel. Sequencing was performed with an ABI Prism BigDye terminator cycle sequencing kit v3.1 and an ABI PRISM 3730 automatic sequencer.

\subsection{Data Analysis}

ITS sequences were edited with SeqMan (DNASTAR Package). Alignments were performed with Clustal X 
Version 1.81 [28] and adjusted manually with BioEdit Version 5.0.9 [29]. Maximum parsimony analysis was conducted with Paup* 4.0b 10 [30] using a heuristic search and tree bisection reconnection (TBR) branch swapping with 1000 search replicates; a random sequence was added to each replicate. Gaps were treated as missing data. Character states were treated as equally weighted and unordered. Four ITS sequences of $T$. pseudoexcavatum G. Moreno et al. were used as the outgroup. To indicate the phylogenetic diversity within the $T$. indicum complex, 4 ITS sequences of the sibling species T. melanosporum Vittad. were included in the phylogenic analysis.

\subsection{Mycorrhizal Synthesis}

The fully mature ascocarps of $T$. indicum used in mycorrhizal synthesis were commercially acquired from a wild edible fungous market in Kunming, Yunnan, China, and the origins were unknown. Seeds of Q. pannosa provided by the Kunming Botanical Garden were used to produce seedlings following the method in [5]. The Po. yunnanensis seedlings were propagated by the traditional cutting \& layering method. The methods for the production of $T$. indicum s.l. mycorrhizae on host trees and the examination of mycorrhizae followed the protocols in [5].

\section{Results}

\subsection{Morphological Characters of Mycorrhizae}

Tuber indicum s.l. $\times$ Poplus yunnanensis (Figure 1).

Mycorrhizal system unramified to monopodial-pinnate, with $1-2$ orders of ramification, brown to light brown in color; short-distance exploration type (Figure 1(a)). Main axes 1 - $3.5 \mathrm{~mm}$ long, 0.7 - $1.5 \mathrm{~mm}$ in di-

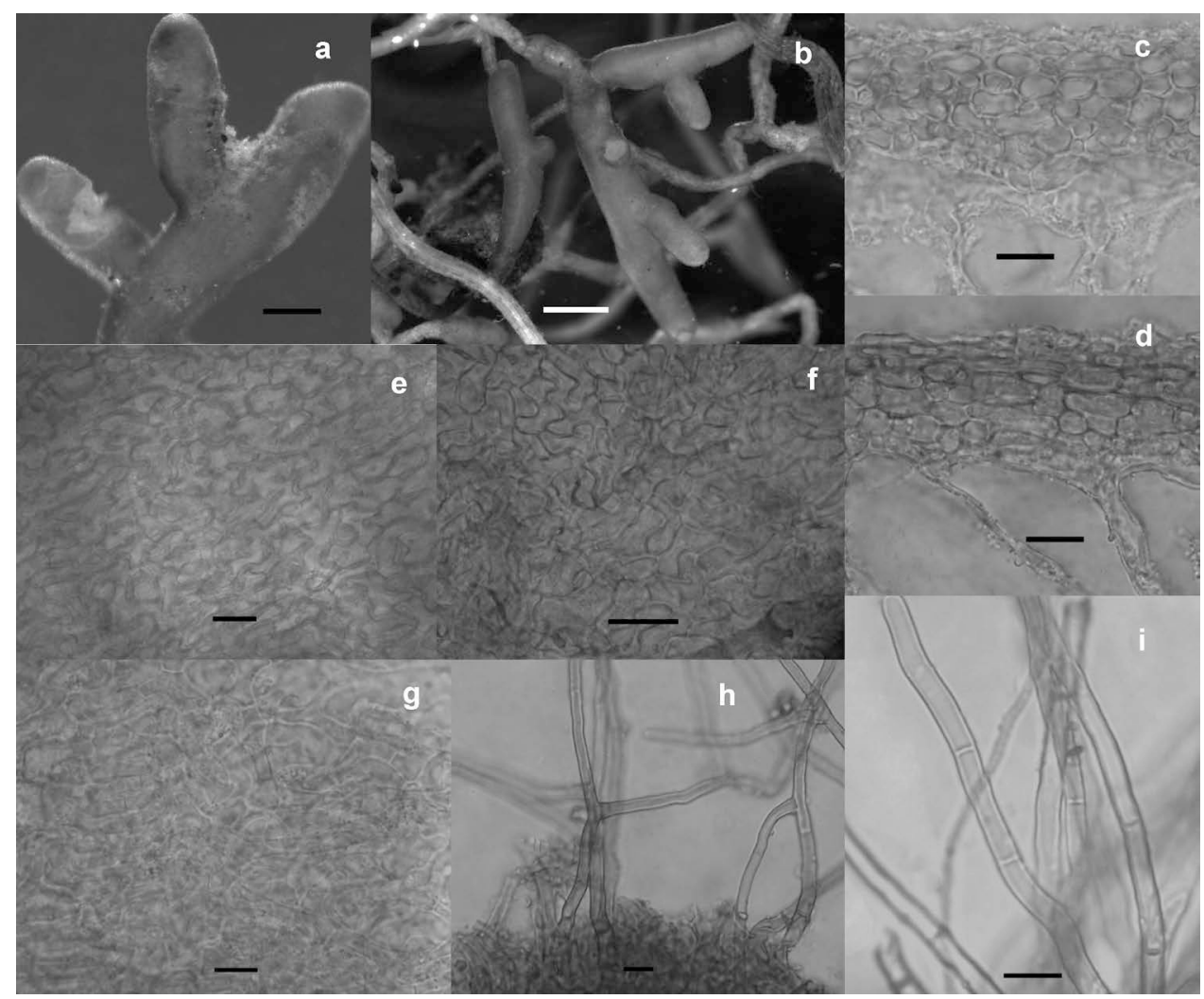

Figure 1. Mycorrhizae formed by T. indicum s.l. on Po. yunnanensis. (a) Natural mycorrhizae (bar $=200 \mu \mathrm{m}$ ); (b) Synthesized mycorrhizae (bar = $2000 \mu \mathrm{m})$; (c) Cross-section of mantle (bar = 10 $\mu \mathrm{m})$; (d). Longitudinal section of mantle (bar = $10 \mu \mathrm{m})$; (e) Outer mantle layer (bar = $10 \mu \mathrm{m})$; (f) Inner mantle layer (bar = $10 \mu \mathrm{m})$; (g) Hyphal net on mantle (bar = $10 \mu \mathrm{m})$; (h)-(i) Emanating hyphae (bar $=10 \mu \mathrm{m})$. 
ameter, straight or slightly bent. Unramified ends 0.5 - $3 \mathrm{~mm}$ long, 0.5 - $0.8 \mathrm{~mm}$ in diameter, straight, cylindrical or slightly tapering, apex round, tips usually lighter than the other parts (Figure 1(b)). Surface smooth or woolly with whitish emanating hyphae; emanating hyphae distinct, numerous, and distributed unequally.

Cross-section of mantle 15 - $25 \mu$ m thick, pseudoparenchymatous composed of 4 - 6 layers with elliptical to hyphal cells $3-13 \times 2-8 \mu \mathrm{m}$, walls thin or slightly thick, light brown, slightly discernible with different layers (Figure 1(c)). Longitudinal section of mantle 18 - $25 \mu \mathrm{m}$ thick, pseudoparenchymatous composed of 5 - 7 layers of elliptical to hyphal cells $4-20 \times 2-8 \mu \mathrm{m}$, walls thin or slightly thick, light brown, subglobose to elliptic, slightly discernible with different layers (Figure 1(d)). The tip in transverse sections same as in other parts but with smaller cells. Hartig net reaches the 1 - 2 layers of cortex cells, composed of 1 - 2 layers of hyphal cells, colorless, subglobose, 1 - $3 \mu \mathrm{m}$ in diameter.

Mantle in plan views is covered by a hyphal network, especially in regions of growth (Figure $1(\mathrm{~g})$ ). The surface net 1 - 2 layers, formed by anastomosed and irregularly connected hyphae, 3 - $5 \mu \mathrm{m}$ in diameter, 5 - $12 \mu \mathrm{m}$ between septa, cell walls thin to slightly thick, smooth, colorless to yellowish brown. Outer mantle layers pseudoparenchymatous epidermoid with irregularly polygonal and sinuous cells interlocked in a puzzle-like pattern, cells 8 - $25 \times 4-10 \mu \mathrm{m}, 6$ - 8 cells in a square of $20 \times 20 \mu \mathrm{m}$, thick walled, with yellowish brown walls, 1 - 2 $\mu \mathrm{m}$ thick, not gelatinous (Figure 1(e)). Inner mantle layers pseudoparenchymatous or a transitional type between plectenchymatous and pseudoparenchymatous, cells $7-18 \times 3-10 \mu \mathrm{m}, 6$ - 9 cells in a square of $20 \times 20$ $\mu \mathrm{m}$, thin walled or slightly thick walled (Figure $1(\mathrm{f})$ ). Mantle structures of the very tips same as in other parts of the mycorrhizae but with smaller cells.

Emanating hyphae growing from hyphal net, loosely woolly, yellowish brown to blackish brown, cylindrical, tips rounded or tapering, thin walled, smooth, straight or bent, 25 - $280 \mu \mathrm{m}$ long, 2 - $4 \mu \mathrm{m}$ in diameter at the top, 3 - $5 \mu \mathrm{m}$ in diameter at the base, septate, 20 - $80 \mu \mathrm{m}$ long between two septa, ramifications frequent and almost perpendicular branching near base, clamps lacking (Figure 1(h) and Figure 1(i)).

Tuber indicum s.l. $\times$ Quercus pannosa (Figure 2).

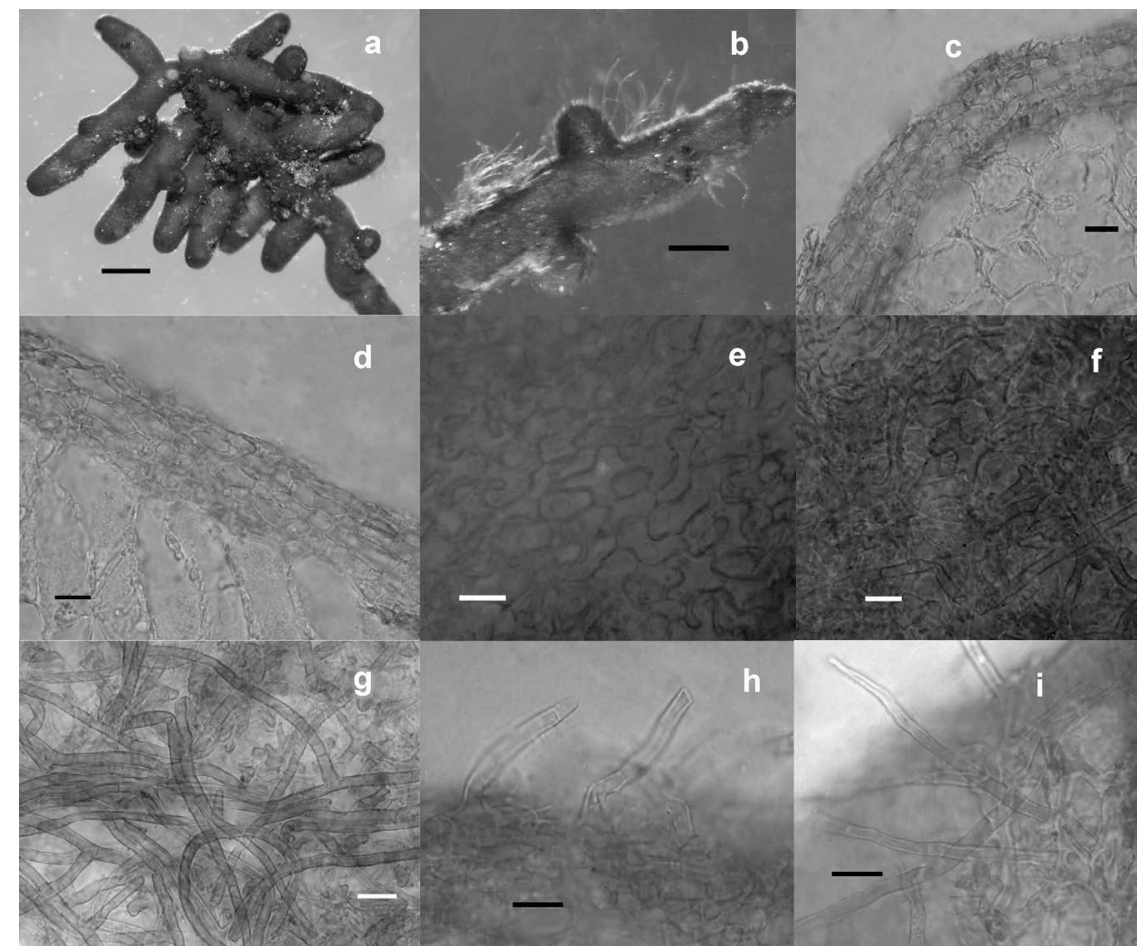

Figure 2. Mycorrhizae formed by T. indicum s.l. on Q. pannosa. (a) Type of ramification (bar = $500 \mu \mathrm{m})$; (b) Mycorrhizal tips with emanating hyphae (bar = $150 \mu \mathrm{m})$; (c) Cross-section of the mantle (bar = $10 \mu \mathrm{m})$; (d) Longitudinal section of the mantle (bar = $10 \mu \mathrm{m}$ ); (e) Mantle in plan views (bar $=10 \mu \mathrm{m}$ ); (f) Hyphal net on the mantle (bar $=10$ $\mu \mathrm{m})$; (g) Emanating hyphae in plan views (bar = $10 \mu \mathrm{m})$; (h) \& (i) Emanating hyphae in transverse views (bar $=10 \mu \mathrm{m})$. 
Mycorrhizal system unramified, monopodial-pinnate to monopodial-pyramidal, with 1 - 3 orders of ramification, light brown when young, brown to darkish brown; short-distance exploration type (Figure 2(a)). Main axes 0.8 - $3.5 \mathrm{~mm}$ long, 0.3 - $0.5 \mathrm{~mm}$ in diameter, straight or slightly bent. Unramified ends 0.3 - $2 \mathrm{~mm}$ long, 0.2 - 0.5 mm in diameter, straight or rarely slightly bent, cylindrical or slightly tapering, apex round (Figure 2(b)). Surface smooth or woolly with whitish emanating hyphae; emanating hyphae distinct, numerous, distributed unequally.

Cross-section of mantle 12 - $25 \mu \mathrm{m}$ thick, pseudoparenchymatous composed of 4 - 7 layers of elliptical to hyphal cells, cells 3 - $15 \times 2$ - $6 \mu \mathrm{m}$, walls thin or slightly thick, indiscernible with different layers (Figure 2(c)). Longitudinal section of mantle 18 - $25 \mu \mathrm{m}$ thick, pseudoparenchymatous composed of 5 - 7 layers of subglobose hyphal cells; cells 3 - $25 \times 2$ - $6 \mu \mathrm{m}$, walls thin or slightly thick, indiscernible with different layers (Figure 2(d)). The tip in transverse sections same as in other parts but with smaller cells. Hartig net reaches the 1 - 2 layers of cortex cells, composed of 1 - 2 layers of hyphal cells, colorless, subglobose, 1 - $3 \mu \mathrm{m}$ in diameter.

Mantle in plan views is covered by a hyphal network, especially in regions of growth (Figure 2(f)). Surface net 1 - 3 layers, formed by anastomosed and irregularly connected hyphae, 3 - $8 \mu \mathrm{m}$ in diameter, 6 - $12 \mu \mathrm{m}$ between septa, cell walls thin to slightly thick, smooth, colorless to yellowish brown. Mantle indiscernible with different layers, composed of pseudoparenchymatous epidermoid with irregularly polygonal cells interlocked in a puzzle-like pattern, cells 8 - $25 \times 5-15 \mu \mathrm{m}, 4-8$ cells in a square of $20 \times 20 \mu \mathrm{m}$, thick walled, with pale brown walls, 0.5 - $1.5 \mu \mathrm{m}$ thick, not gelatinous (Figure 2(e)). Mantle structures of the very tips same as in other parts of mycorrhizae but with smaller cells.

Emanating hyphae growing from both the outer mantle layer cells and hyphal net, loosely woolly, whitish to yellowish brown, cylindrical, tips rounded, thin walled, smooth, straight or bent, 60 - $350 \mu \mathrm{m}$ long, 2 - $3 \mu \mathrm{m}$ in diameter at the top, 3 - $4 \mu \mathrm{m}$ in diameter at the base, septate, 20 - $60 \mu \mathrm{m}$ long between two septa, ramifications frequent and almost 60 - 90 degree branching, clamps lacking (Figures 2(g)-(i)).

\subsection{Phylogenetic Analysis}

Forty-nine ITS sequences of T. indicum s.l. were used in the phylogenetic analysis (Table 1), including 23 from ascomata, 15 from natural mycorrhizae and 11 from synthesized mycorrhizae. Of the 566 total characters analyzed, 371 characters were constant, 18 were parsimony uninformative, and 177 were parsimony informative. The most parsimonious tree (Figure 3 ) included 261 steps $(\mathrm{CI}=0.8697, \mathrm{RI}=0.9693)$.

The ITS phylogenetic tree (Figure 3) revealed that T. indicum s.l. is well separated into Group A and Group B. Two subclades, Group A and T. melanosporum, cluster in one clade that is a sister Group to with Group B with 100\% bootstrap support. Thirty-one sequences of T. indicum s.l. clustered in Group A, and 18 clustered in Group B (the geographic distribution of the two groups is shown in Figure 4). Eighteen ITS sequences in Group A and 8 ITS sequences in Group B were from mycorrhizae (sequence origins are shown in Table 1).

\section{Discussion}

Using blast and ITS sequences from natural mycorrhizae in the NCBI database, we confirmed the symbiotic relationships between T. indicum s.l. and Q. pannosa, Po. yunnanensis, Ca. mollissima, Pi. armandii and Pi. yunnanensis. All Q. pannosa and Po. yunnanensis seedlings formed mycorrhizal systems with T. indicum on artificially controlled substrates. Before this study, eight indigenous trees of the genera Quercus, Cyclobalanopsis, Castanea, Carpinus and Pinus were successfully inoculated with T. indicum s.l. [4]-[7]. Tuber indicum s.l. has also been reported to form mycorrhizae with two North American trees, Pi. taeda and Carya illinoinensis [8], and five European trees, Q. pubescens, Q. cerris, Q. ilex, Co. avellana and Pi. pinea [10]-[13] under artificially controlled conditions. Currently, sixteen trees are known to be symbiotic with T. indicum s.l. The higher diversity of the hosts indicates that $T$. indicum s.l. has wider host compatibility and higher ecological adaptability, suggesting that this species is more suitable than T. menosporum for artificial cultivation.

For the first time, we found Chinese black truffle mycorrhizae on poplars. Prior this study, the white truffles $T$. magnatum Pico and T. rapaeodorum Tul. \& C. Tul. were found in association with the European poplar tree Po. alba L. [31]-[33]. The confirmation of the mycorrhizal relationship between T. indicum s.l. and Po. yunnanensis is of particular practical importance because Yunnan aspen seedlings can be easily produced by asexual reproduction and grow more rapidly. The Yunnan aspen is widely distributed in the middle-lowlands (altitude 1600 $3500 \mathrm{~m}$ ) of southwestern China and is an important species for afforestation because it grows quickly [34]. The 


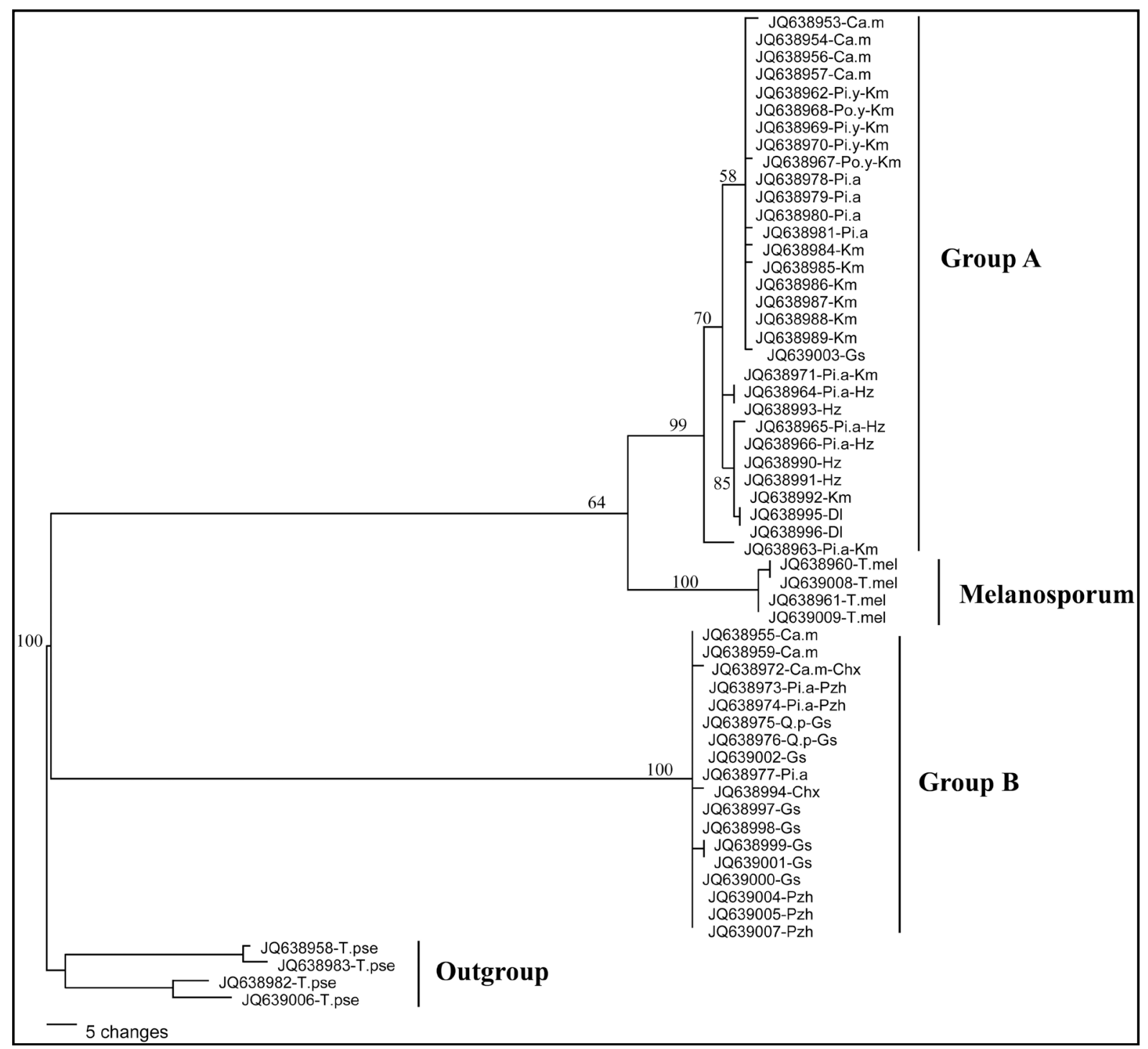

Figure 3. One of the 32 most parsimonious trees obtained from the analysis of the ITS sequences. $(\mathrm{Km}=\mathrm{Kunming}$, Gs $=$ Gongshan, $\mathrm{Hz}=$ Huize, $\mathrm{Dl}=$ Dali, $\mathrm{Chx}=$ Chuxiong, $\mathrm{Pzh}=$ Panzhihua).

successful production of mycorrhizae using Po. yunnanensis seedlings and T. indicum s.l. confirmed the feasibility of using this tree on truffle conservation and plantations.

Tuber indicum s.l. mycorrhizae are characterized by a mantle composed of epidermoid cells interlocked in a puzzle-like pattern and woolly emanating hyphae that branch almost perpendicularly [5] [10]-[13] [35]. The mycorrhizae of $T$. melanosporum, a member of the same phylogenetic lineage, share all these characters with $T$. indicum s.l. except the hyphal net on the surface of the mantle, as shown in previous studies [36] [37]. However, a surface hyphal net on the mantle was also detected in T. indicum s.l. mycorrhizae in our study. These newly discovered characters broaden the diversity of $T$. indicum s.l. mycorrhizae, making it impossible to distinguish the mycorrhizae of these two species.

Geographical origins have been used to explain the inter-clade variability in T. indicum s.l. [20] [22]. The samples from Kunming, Huize, Dali and Gongshan, including T. indicum s.l. mycorrhizae and ascomata collected in situ, belonged to Group A, whereas samples from Gongshan, Panzhihua and Chuxiong belonged to Group B (shown in Figure 4). Groups A and B in our study are comparable to clades I and II, respectively, described by Wang et al. [22]. However, the origins of the two separate clades determined by Wang et al. [22] are different from the origins determined in our study. Samples from Gongshan all belonged to clade II in Wang et 


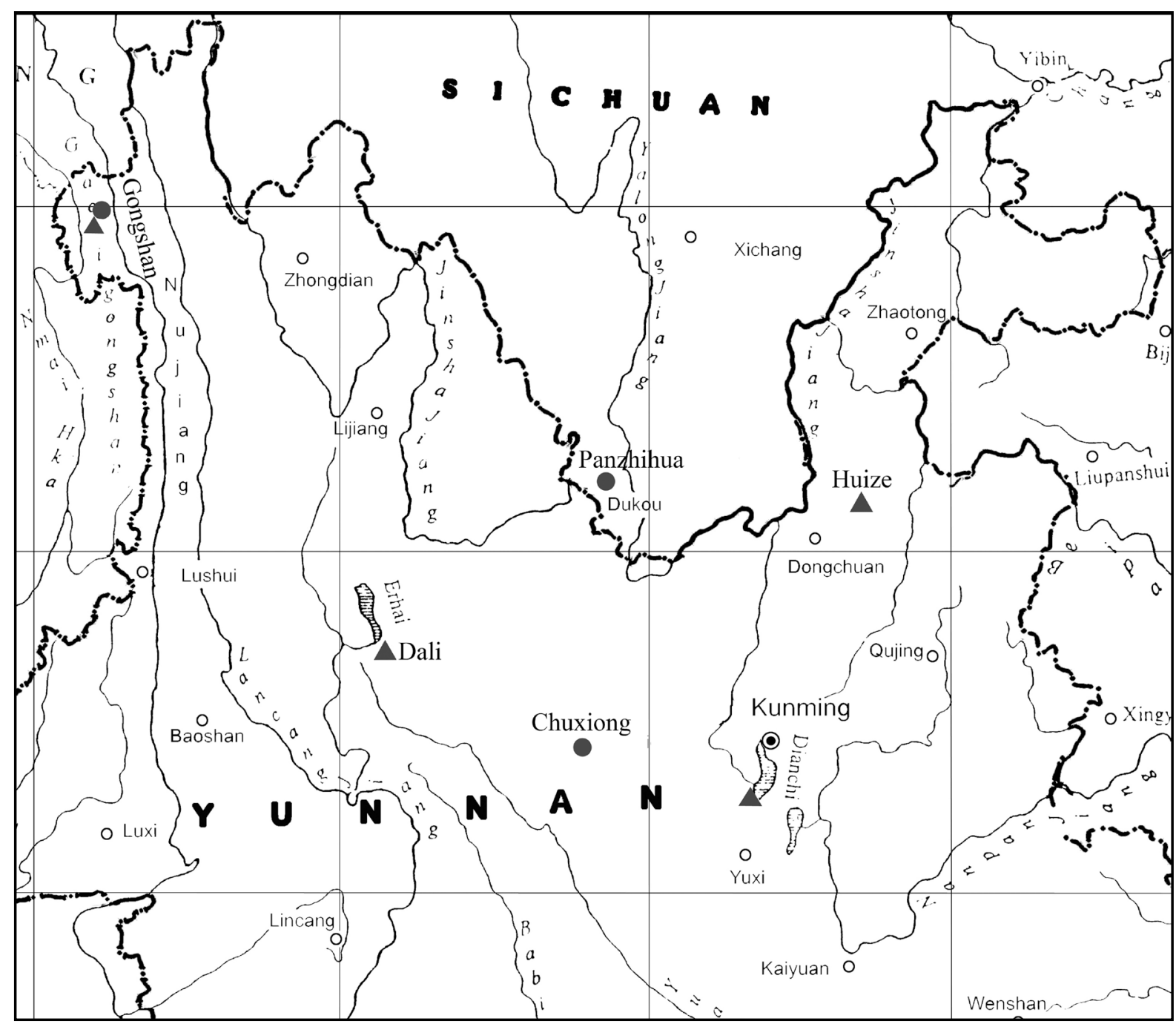

Figure 4. Geographic distribution of the two groups within T. indicum s.l. (triangles indicate the origins of Group A; circles indicate the origins of Group B).

al.'s study [22] but belonged to both Group A and Group B in our study. In addition, samples from Huize belonged to Group A and those from Chuxiong belonged to Group B in our study, whereas samples from Huize belonged to clade II and those from Chuxiong belonged Group I in Wang et al.’s study [22]. Because the samples were collected in situ in this study, our results indicate that two groups are not geographically distinct, supporting the results of Zhang et al. [23] and Chen et al. [15]. In our study, Pi. armandii was the natural host of five samples in Group A and of two samples in Group B, indicating that the two groups do not have distinct natural host preferences. Moreover, no host preference in the inoculation experiments was detected for Group A or Group B, as both groups included ITS sequences from mycorrhizae on Pi. armandii and Ca. mollissima. Although only ITS rDNA sequence was used in our study, the two clades in our phylogenic tree are consistent with the topologies inferred from ITS, LSU and $\beta$-tubulin sequences in Chen et al.'s study [14]. Our results support Chen et al.'s conclusion [15] that there are two cryptic species in the T. indicum complex. Furthermore, interclade differences in mycorrhizal morphology were not detected in our study, and the lack of distinct mycorrhizal morphologies could contribute to the presence of two cryptic species in the T. indicum complex.

\section{Acknowledgements}

The first author is very grateful for the help of Dr. X. H. Wang, who critically reviewed the manuscript and offered invaluable suggestions. Dr. Y. Wang is greatly appreciated for his help with assessing the mycorrhizae 
formed and for his kind encouragement. Many thanks are given to Lawrence Glacy for his linguistic assistance and to our colleagues who helped collect specimens and perform the field work. This study was financed by the National Science Foundation of China (No. 30470011, 31270075); the Joint Founds of the National Science Foundation of China and Yunnan Province Government (No. U1202262); the Yunnan Program of Innovation to strong provinces by Science \& Technology (No. 2009AC013); the Key Laboratory for Plant Biodiversity and Biogeography of East Asia (KLPB), Kunming Institute of Botany, Chinese Academy of Sciences (No. 0806361121); the Key Laboratory of Food Fermentation \& Brewing Technology, State Ethnic Affairs Commission of the People's Republic of China (2012SY05); and Natural Science Foundation of Ningxia (NZ13089).

\section{References}

[1] Zhang, B.C. and Minter, D.W. (1988) Tuber himalayense sp. nov. with Notes on Himalayan Truffles. Transactions of the British Mycological Society, 91, 593-597. http://dx.doi.org/10.1016/S0007-1536(88)80032-9

[2] Chen, J. (2007) Taxonomy and Phylogeny of the Genus Tuber in China. Ph.D. Dissertation, Kunming Institute of Botany, Chinese Academy of Sciences, Kunming, 81-103.

[3] Zhang, D.C. and Wang, Y. (1990) Study on Chinese Truffle and Its Ecology. Edible Fungi of China, 9, 25-27.

[4] Chen, B.T. (2003) Inoculation and Infection of Tuber spp. and Establishment of Truffle Plantation. Guizhou Forestry Science and Technology, 31, 10-14.

[5] Geng, L.Y., Wang, X.H., Yu, F.Q., Deng, X.J., Tian, X.F., Shi, X.F., Xie, X.D., Liu, P.G. and Shen, Y.Y. (2009) Mycorrhizal Synthesis of Tuber indicum with Two Indigenous Hosts, Castanea mollissima and Pinus armandii. Mycorrhiza, 19, 461-467. http://dx.doi.org/10.1007/s00572-009-0247-0

[6] Hu, B.F., Zhu, Z.R., Yuan, X.M., Yin, X.Y., Zhang, X.M., Wang, L., Fang, S., Yang, S. and Liao, W.B. (2004) The mycorrhizal Synthesis of Tuber indicum and Its Affect for Growth and against Disease on the Seedlings. Guizhou Forestry Science and Technology, 32, 19-24.

[7] Hu, B.F., Yun, X.Y., Zhu, Z.R., Yuan, X.M., Yang, A.M., Jin, T.X., Hu, G., Liao, W.B. and Yang, P. (2006) Study on the Inoculation Technology of Tuber sp. for the Mycorrhizal Seedlings. Guizhou Forestry Science and Technology, 34, 15-18.

[8] Bonito, G.M., Trappe, J.M., Donovan, S. and Vilgalys, R. (2011) The Asian Black Truffle Tuber indicum Can Form Ectomycorrhizas with North American Host Plants and Complete Its Life Cycle in Non-Native Soils. Fungal Ecology, 4, 83-93. http://dx.doi.org/10.1016/j.funeco.2010.08.003

[9] Bonito, G.M., Gryganskyi, A.P., Trappe, J.M. and Vilgalys, R. (2010) A Global Meta-Analysis of Tuber ITS rDNA Sequences: Species Diversity, Host Associations and Long-Distance Dispersal. Molecular Ecology, 19, 4994-5008. http://dx.doi.org/10.1111/j.1365-294X.2010.04855.x

[10] Comandini, O. and Pacioni, G. (1997) Mycorrhizae of Asian Black Truffles, Tuber himalayense and T. indicum. Mycotaxon, 63, 77-86.

[11] Douet, J.P., Castroviejo, M., Mabru, D., Chevalier, G., Dupré, C., Bergougnoux, F., Ricard, J.M. and Médina, B. (2004) Rapid Molecular Typing of Tuber melanosporum, T. brumale and T. indicum from Tree Seedlings and Canned Truffles. Analytical and Bioanalytical Chemistry, 379, 668-673. http://dx.doi.org/10.1007/s00216-004-2643-9

[12] García-Montero, L.G., Di Massimo, G., Manjón, J.L. and García-Abril, A. (2008) New Data on Ectomycorrhizae and Soils of the Chinese Truffles Tuber pseudoexcavatum and Tuber indicum, and Their Impact on Truffle Cultivation. Mycorrhiza, 19, 7-14. http://dx.doi.org/10.1007/s00572-008-0198-x

[13] Zambonelli, A., Tibiletti, E. and Pisi, A. (1997) Caratterizzazione Anatomo-Morfologica Delle Micorrize di Tuber indicum Cooke \& Massee su Pinus pinea L. e Quercus cerris L. Micologia Italiana, 26, 29-36.

[14] Wang, Y. and Liu, P.G. (2009) Achievements and Challenges of Research on Truffles in China. Acta Botanica Yunnanica, 16, 1-9.

[15] Chen, J., Guo, S.X. and Liu, P.G. (2011) Species Recognition and Cryptic Species in the Tuber indicum Complex. PLoS ONE, 6, 1-10. http://dx.doi.org/10.1371/journal.pone.0014625

[16] Hu, H.T., Wang, Y. and Hu, B.Y. (2005) Cultivation of Tuber formosanum on Limed Soil in Taiwan. New Zealand Journal of Crop and Horticultural Science, 33, 363-366. http://dx.doi.org/10.1080/01140671.2005.9514371

[17] García-Montero, L.G., Díaz, P., Di Massimo, G. and García-Abril, A. (2010) A Review of Research on Chinese Tuber Species. Mycological Progress, 9, 315-335. http://dx.doi.org/10.1007/s11557-009-0647-8

[18] Huang, J.Y., Hu, H.T. and Shen, W.C. (2009) Phylogenetic Study of Two Truffles, Tuber formosanum and Tuber furfuraceum, Identified from Taiwan. FEMS Microbiology Letters, 294, 157-171. http://dx.doi.org/10.1111/j.1574-6968.2009.01571.x 
[19] Mabru, D., Dupré, C., Douet, J.P., Leroy, P., Ravel, C., Ricard, J.M., Medina, B., Castroviejo, M. and Chevalier, G. (2001) Rapid Molecular Typing Method for the Reliable Detection of Asiatic Black Truffle (Tuber indicum) in Commercialized Products: Fruiting Bodies and Mycorrhizal Seedlings. Mycorrhiza, 11, 89-94. http://dx.doi.org/10.1007/s005720100103

[20] Paolocci, F., Rubini, A., Granetti, B. and Arcioni, S. (1997) Typing Tuber melanosporum and Chinese Black Truffle Species by Molecular Markers. FEMS Microbiology Letters, 153, 255-260. http://dx.doi.org/10.1111/j.1574-6968.1997.tb12582.x

[21] Roux, C., Delmas-Sejalon, N., Martins, M., Parguey-Leduc, A., Dargent, R. and Bécard, G. (1999) Phylogenetic Relationships between European and Chinese Truffles Based on Parsimony and Distance Analysis of ITS Sequences. FEMS Microbiology Letters, 180, 147-155. http://dx.doi.org/10.1111/j.1574-6968.1999.tb08789.x

[22] Wang, Y.J., Tan, Z.M., Zhang, D.C., Murat, C., Jeandroz, S. and Le Tacon, F. (2006) Phylogenetic and Populational Study of the Tuber indicum Complex. Mycological Research, 110, 1034-1045. http://dx.doi.org/10.1016/j.mycres.2006.06.013

[23] Zhang, L.F., Yang, Z.L. and Song, D.S. (2005) A Phylogenetic Study of Commercial Chinese Truffles and Their Allies: Taxonomic Implications. FEMS Microbiology Letters, 245, 85-92. http://dx.doi.org/10.1016/j.femsle.2005.02.028

[24] Agerer, R. (1987-2002) Color Atlas of Ectomycorrhizae. Einhorn-Verlag, Schwäbisch Gmünd.

[25] Doyle, J.J. and Doyle, J.L. (1987) A Rapid DNA Isolation Procedure from Small Quantities of Fresh Leaf Tissues. Phytochemical Bulletin, 19, 11-15.

[26] White, T.J., Bruns, T.D., Lee, S.B. and Taylor, J.W. (1990) Amplification and Direct Sequencing of Fungal Ribosomal RNA Genes for Phylogenetics. In: Innis, M.A., Gelfand, D.H., Sninsky, J.J. and White, T.J., Eds., PCR Protocols: A Guide to Methods and Applications, Academic Press, New York, 315-322. http://dx.doi.org/10.1016/B978-0-12-372180-8.50042-1

[27] Paolocci, F., Rubini, A., Granetti, B. and Arcioni, S. (1999) Rapid Molecular Approach for a Reliable Identification of Tuber spp. Ectomycorrhizae. FEMS Microbiology Ecology, 28, 23-30. http://dx.doi.org/10.1111/j.1574-6941.1999.tb00557.x

[28] Thompson, J.D., Gibson, T.J., Plewniak, F., Jeanmougin, F. and Higgins, D.G. (1997) The CLUSTAL_X Windows Interface: Flexible Strategies for Multiple Sequence Alignment Aided by Quality Analysis Tools. Nucleic Acids Research, 25, 4876-4882. http://dx.doi.org/10.1093/nar/25.24.4876

[29] Hall, T.A. (1999) BioEdit: A User-Friendly Biological Sequence Alignment Editor and Analysis Program for Windows 95/98/NT. Nucleic Acids Symposium Series, 41, 95-98.

[30] Swofford, D.L. (2002) PAUP*: Phylogenetic Analysis Using Parsimony (*and Other Methods), 4.0b4a. Sinauer Associates, Sunderland, Massachusetts.

[31] Angelini, P. and Granetti, B. (1995) La micorrizazione di alcuni cloni micropropagati di Populus alba L. con Tuber magnatum Pico. Giornale Botanico Italiano, 129, 1161-1177. http://dx.doi.org/10.1080/11263509509436469

[32] Granetti, B. (1995) Caratteristiche morfologiche, biometriche e strutturali delle micorrize di Tuber di interesse economico. Micologia Italiana, 2, 101-117.

[33] Jakucs, E. (2002) Ectomycorrhizae of Populus alba L. in South Hungary. Phyton-Annales Rei Botanicae, 42, $199-210$.

[34] He, C.Z., Che, P.Y., Zhou, X.T., Duan, A.A., Wang, D.X. and Xin, P.R. (2010) A Survey of Research Progress on Gene Resources of Populus yunnanens. Journal of Southwest Forestry University, 30, 83-88.

[35] Hu, H.T. (1992) Tuber formosanum sp. nov. and Its Mycorrhizal Associations. Journal of the Experimental Forest, National Taiwan Univesity, 6, 79-86.

[36] Pérez, F., Palfner, G., Brunel, N. and Santelices, R. (2007) Synthesis and Establishment of Tuber melanosporum Vitt. Ectomycorrhizae on Two Nothofagus Species in Chile. Mycorrhiza, 17, 627-632. http://dx.doi.org/10.1007/s00572-007-0140-7

[37] Rauscher, T. and Chevalier, G. (1995) Tuber melanosporum. In: Agerer, R., Ed., Colour Atlas of Ectomycorrhizae, Plate 87, Einhorn-Verlag, Schwäbisch Gmünd. 
Scientific Research Publishing (SCIRP) is one of the largest Open Access journal publishers. It is currently publishing more than 200 open access, online, peer-reviewed journals covering a wide range of academic disciplines. SCIRP serves the worldwide academic communities and contributes to the progress and application of science with its publication.

Other selected journals from SCIRP are listed as below. Submit your manuscript to us via either submit@scirp.org or Online Submission Portal.
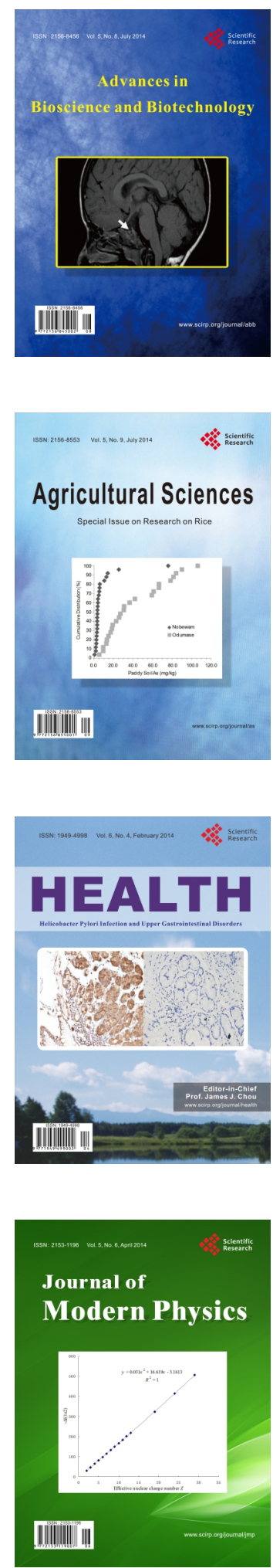
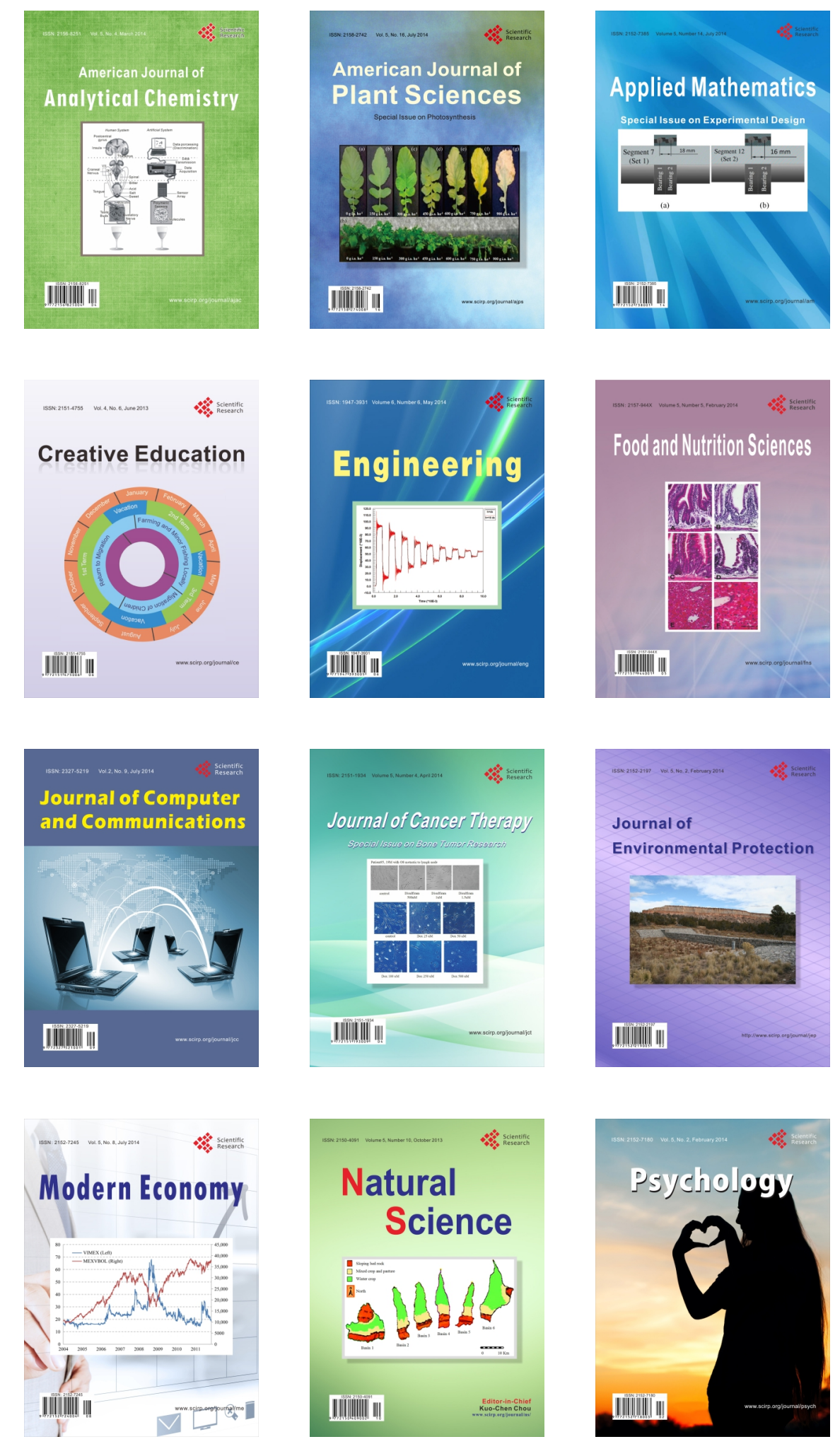